\title{
CONVERGÊNCIAS \\ E DIVERGÊNCIAS \\ DAS PRÁTICAS DE \\ AUTOAVALIAÇÃO \\ INSTITUCIONAL EM IES \\ PÚBLICA E PRIVADA \\ NA PERCEPÇ̃̃O DA \\ COMUNIDADE ACADÊMICA
}

\section{ELISA ANTONIA RIBEIRO}

\section{RESUMO}

Este artigo discute os fatores que interferem na institucionalização da avaliação da educação superior como um campo de forças. Analisa, também, o documento oficial que serviu de base para que as Instituições de Ensino Superior (IES) deflagrassem o processo de implementação da avaliação institucional proposta pelo Sistema Nacional de Avaliação da Educação Superior (Sinaes). Por meio de uma pesquisa de campo, realizada em duas IES do Estado de Minas Gerais, envolvendo dirigentes, docentes e discentes, buscou-se compreender o processo de construção, execução e utilização dos resultados da autoavaliação institucional AAI pela comunidade acadêmica. Nesse artigo o foco será em relação à avaliação docente, destacando que alguns aspectos relativos à docência estão sendo alterados após o resultado da AAI. Podemos concluir que, na IES privada, os resultados da AAI impactuam de forma mais incisiva no aspecto relacionamento professor $X$ aluno e, na IES pública, o impacto foi na alteração da condução da aula. 


\section{RESUMEN}

Este artículo discute los factores que interfieren en la institucionalización de la evaluación de la educación superior como un campo de fuerzas. Analiza, también, el documento oficial que sirvió de base para que las Instituciones de Enseñanza Superior (IES) propagasen el proceso de implementación de la evaluación institucional propuesta por el Sistema Nacional de Evaluación de la Educación Superior (Sinaes). Por medio de una investigación de campo, realizada en dos IES del Estado de Minas Gerais, que incluyó a dirigentes, docentes y discentes, se buscó comprender el proceso de construcción, ejecución y utilización de los resultados de la autoevaluación institucional (AAI) por la comunidad académica. En este artículo el foco estará en la evaluación docente, destacando que algunos aspectos relativos a la docencia están siendo alterados después del resultado de la AAI. Podemos concluir que en la IES privada, los resultados de la AAI impactan de forma más incisiva en la relación profesor X alumno y, en las IES pública, el impacto fue en la alteración de la conducción de la clase.

PALABRAS CLAVE: POLÍTICAS PÚBLICAS • SINAES •

EVALUACIÓN INSTITUCIONAL・PRÁCTICA DOCENTE.

\section{ABSTRACT}

This article discusses the factors that interfere with the establishment of higher education assessment as a field of forces. It also analyzes the official document which constituted the basis for the Higher Education Institutions (HEI) to trigger the process of implementating the institutional assessment proposed by the National System for the Assessment of Higher Education (Sinaes). Through field research, carried out in two HEIs in the State of Minas Gerais, involving administrators, teachers and students, we sought to understand the process of building, running and using the results of institutional self-assessment (ISA) by the academic community. In this article we focus on teacher assessment, noting that some aspects of teaching are being modified after the ISA results. We conclude that, in private HEIs, the ISA results have a stronger impact on student-teacher relationship, while in public HEIs the impact is on the change in class conduction. 


\section{INTRODUÇÃO}

Este artigo decorre da tese de doutorado produzida no Programa de Pós-Graduação em Educação da Faculdade de Educação da Universidade Federal de Uberlândia (UFU) que investigou o processo de efetivação da autoavaliação institucional (AAI) determinado pelo Sistema Nacional de Avaliação da Educação Superior (Sinaes) às Instituições de Ensino Superior (IES), e os aspectos da atuação docente que estão sendo alterados a partir dos resultados dessa avaliação na percepção dos atores institucionais.

Como opção metodológica para o presente artigo, optou-se por desenvolver uma reflexão acerca dos precedentes avaliativos e dos fatores que interferem na institucionalização da avaliação da educação superior como um campo de forças. Complementa a reflexão o estudo e análise do documento base oficial $^{1}$ que contém os fundamentos legais e as orientações para as IES de como operacionalizar a execução da Lei n. 10.861 de 14 de abril de 2004 que instituiu o Sinaes. Em seguida, apresenta-se os resultados da pesquisa empírica realizada no doutorado cuja ênfase recaiu na identificação dos elementos 
que contribuíram para o sucesso e/ou fracasso da implantação da proposta de AAI, nos fatores interferentes na consolidação da cultura avaliativa, no modo como os resultados da avaliação são incorporados na prática dos docentes e as tendências do processo após a conclusão dos dois ciclos avaliativos de cada instituição.

A pesquisa empírica foi desenvolvida no período de 2006 a 2009, em duas instituições de ensino superior (IES), uma pública - Centro Federal de Educação Tecnológica de Minas Gerais (CEFET-MG), Campus/Araxá - e uma privada - Centro Universitário do Planalto de Araxá(UNIARAXÁ). Participaram como sujeitos da pesquisa os dirigentes, os docentes e os discentes. A escolha dos dirigentes deveu-se ao fato de que são eles os responsáveis pela formulação e condução das políticas de avaliação interna. Os docentes também foram selecionados porque são eles os mais envolvidos nos resultados da AAI, a partir da constatação de que, nas duas IES, o foco da AAI está na avaliação docente. Tendo essa referência, os discentes foram "ouvidos" com o objetivo de levantar a sua percepção sobre quais os aspectos da atuação docente estariam sendo modificados após os resultados da autoavaliação. Para participar da pesquisa, os docentes e discentes deveriam ter vivenciado pelo menos um processo da avaliação institucional AI. Contou-se, na IES pública, com a seguinte amostragem: dirigentes (um diretor geral, dois diretores de graduação, que alternaram no cargo durante a realização da pesquisa e um presidente da CPA), 10 docentes e 35 discentes. $\mathrm{Na}$ IES privada, a amostragem estabelecida foi: dirigentes (dois reitores, que alternaram no cargo durante a realização da pesquisa), 56 docentes e 318 discentes. Para o grupo de dirigentes foi utilizada a técnica da entrevista semiestruturada, mediante a identificação nominal dos entrevistados, com autorização. Para o grupo de docentes e discentes foi aplicado um questionário com questões fechadas e abertas. Complementou a pesquisa a análise dos projetos de AAI e dos relatórios finais do $1^{\circ}$ e $2^{\circ}$ ciclos avaliativos e o acompanhamento de notícias sobre a avaliação institucional nos sites das instituições. A interpretação dos dados foi realizada com o emprego da técnica de Análise de Conteúdo, baseada em Bardin (1999), conjugada com a análise de viés quantitativa, por meio da triangulação dos dados. Durante a interpretação dos universos empíricos e a concomitante elaboração da escrita dos resultados, atentou-se para o rigor do 
método, imprescindível ao próprio pesquisar, uma vez que a autora da tese participou efetivamente na execução de todas as fases do processo de autoavaliação em ambas as instituições. Durante essas reflexões, considerou-se que "a universidade e tudo o que produz não são coisas, dados e fatos observáveis, realidades prontas e acabadas, a serem radiografadas, esquadrinhadas, analisadas e julgadas em seus resultados e produtos, nem ideias provisórias e precariamente encarnadas no espaço e no tempo" (Coelho, 200o, P. 45). Assim, a universidade em análise é um campo de força em que os seus atores institucionais buscam, na realização do processo da avaliação institucional, o autoconhecimento e a tomada de decisão para a melhoria dos processos e das práticas internas, bem como o implemento da função social da avaliação.

\section{AVALIAÇÃO INSTITUCIONAL: UM CAMPO DE FORÇAS}

A avaliação opera, no campo ideológico, provocando e promovendo importantes contradições que dificultam a sua compreensão e a tornam um fenômeno social bastante conflituoso. Em virtude disso, a avaliação vem ganhando densidade política e está sendo utilizada como instrumento de poder e estratégia da maioria dos governos nas últimas décadas, e assumindo a função de regulação da educação superior. De acordo com Dias Sobrinho (2003, p. 9), a avaliação: "inscreve-se no terreno das reformas, inovações curriculares, programas e projetos e exerce um papel de real importância na configuração dos modelos das instituições, organizações e sistemas”. Esta visibilidade, conferida à avaliação pelos governos, está referendada no texto elaborado pela Comissão

2 A Comissão Especial de Avaliação (CEA) foi designada pelas Portarias MEC/SESU, N 11, de 28 de abril de 2003 № 19 , de 27 de maio de 2003 , sendo oficialmente instalada Cristóvam Buarque, em 29 de abril de 2003 Especial de Avaliação (CEA) ${ }^{2}$, que subsidiou a elaboração da Lei n. 10.861 de 14 de abril de 2004 a qual originou o Sinaes. No contexto de formulação desta política de avaliação, ficou perceptível a disputa entre grupos que defendem ideias opostas para a função da educação superior.

Esse embate sobre o poder da avaliação das instituições de ensino superior não é tão recente; na metade da década de 1980, em países como Estados Unidos, França, Holanda, Suécia e Inglaterra, a avaliação já era destaque; tanto no meio 
acadêmico quanto como elemento que subsidiou a elaboração das políticas públicas para a educação. Posteriormente estendeu-se para países em desenvolvimento, no início dos anos 1990, com a finalidade de conferir à avaliação o papel de indutora da melhoria da qualidade da gestão de sistemas educacionais como meio de racionalização de recursos públicos para as instituições.

No contexto brasileiro, Gadotti (1995) já mostrava que o tema AI começou a aparecer de forma mais evidente nas publicações acadêmicas a partir dos anos de 1980. É importante reconhecer que a avaliação das instituições ganhou projeção no início de 1990, devido à reconfiguração das funções do Estado, quando este assume as prerrogativas do Estado Avaliador (Polidori; FonseCA; LARrosa, 2007). Ou seja, a avaliação tornouse um dispositivo que funcionaliza as reformas, nitidamente, no campo da educação superior (DiAs Sobrinho, 2003).

Para Santos (2005), os sistemas educacionais de nível superior têm passado, ao longo da sua vigência, por tensões que coincidem com as crises do capitalismo, "na grande maioria dos países foi provocada ou induzida pela perda de prioridade do bem público e pela consequente secagem financeira e descapitalização das universidades públicas. As causas e sua seqüência variaram de país para país” (SANTOS, 2005, P. 13).

No Brasil, a atual crise da universidade é resultado em grande parte da reforma do Estado conduzida nos moldes da reforma gerencial, que programou um novo modelo de Estado e, em consequência, tem produzido o dissenso a respeito dos fins da educação superior e de como o processo de avaliação da universidade deve ser (RIstoff, 1999).

A alteração das funções do Estado, como destacado acima, motivou o embate sobre os fins da educação superior, projetando duas concepções distintas de educação superior. De um lado, temos uma força que postula uma educação promovida e financiada pelo Estado, considerada como bem público e, consequentemente, alinhada à geração e à socialização de conhecimentos capazes de promover a melhoria e a sustentabilidade da própria sociedade. Por outro lado, assiste-se àqueles que defendem uma concepção de educação como bem de consumo, à mercê da lógica do mercado, logo, uma educação orientada para fins mercantilistas, 
deixando ao "mercado educativo" (СAвRIto, 2004, P. 987) a responsabilidade pela produção e distribuição do ensino. São essas concepções antagônicas de educação superior que vêm produzindo a tensão no espaço universitário e gerando as contradições nos princípios, concepções, objetivos e instrumentos que orientam as práticas de avaliação. Por existir essa tensão, a respeito das concepções de educação superior, é que se pode dizer que a avaliação da educação superior não é uma questão meramente técnica; é, portanto, "um dos temas mais complicados e complexos, tanto para quem se dedica à teoria quanto para quem se envolve em sua prática” (Dias Sobrinho, 2004, P. 705).

Embora exista esse campo de força, podemos afirmar que tem havido um intenso esforço e busca, por parte da comunidade acadêmica, na última década, pelo estabelecimento da necessidade de se avaliar a universidade, mas tendo como âncora, o princípio do respeito à sua singularidade. Dias Sobrinho (1997) enfatiza que este princípio é uma questão indelével, pois avaliar uma instituição é: compreender as suas finalidades, os projetos, a missão, o clima, as pessoas, [...], os conflitos, os valores, as crenças. [...] Não há, portanto, um modelo de avaliação pronto para uso geral e indiscriminado, como se houvesse uma forma única de instituição e como se o que se pretende avaliar fosse sempre e em todo lugar uma só e a mesma coisa. [...]. Obviamente, uma universidade participa dos princípios universais das instituições dessa natureza. Entretanto, não há um modelo único e universal de universidade (DiAs Sobrinho, 1997, P. 73).

As bases, portanto, a serem consideradas num processo de AI estão comprometidas com uma proposta de avaliação que vise a transformação da universidade. A avaliação institucional é uma atividade intrínseca a cada instituição e ao sistema como um todo, pois interfere e produz efeitos sobre o seu funcionamento presente e futuro. "A avaliação institucional ocorre em uma entidade viva, que tem sua história composta por seres vivos, heterogêneos e em contínuo processo de crescimento. [...] Por sua vez, os membros da organização têm sua trajetória de vida, experiências, modos de ver e sentir" (LAMPERT, 2008, P. 163). 


\subsection{OS PRECEITOS DA AVALIAÇÃO INSTITUCIONAL}

\section{DE BASE FORMATIVA E PEDAGÓGICA}

Dois são os objetivos de toda AI cuja base é a formação e a promoção do melhoramento da instituição e das pessoas inseridas nesse contexto: o autoconhecimento e a tomada de decisão. O autoconhecimento significa identificar "os acertos e as ineficiências, as vantagens/potencialidades e as dificuldades; envolve um processo de reflexão sobre as razões, as causas das situações positivas e das insuficiências; implica em assumir a responsabilidade efetiva da gestão política e acadêmico-científica da instituição e do sistema como um todo" (Belloni, 2000, P. 23). A mencionada autora também informa que a AI, em uma concepção pedagógica e formativa, está indelevelmente conectada à mudança e à melhoria da qualidade da educação. Acrescenta, ainda, que quando adequadamente desenvolvida, à medida que vai agregando novas dimensões da vida universitária, sem, contudo, abrir mão dos espaços já conquistados, seu poder de provocar mudanças aumenta.

Conceitualmente, Holgado Sánchez e Lampert (2002) consideram o processo de AI:

No es un acto puntual, aislado, oportunista y determinista, que ocurre en determinados tiempos. Constituye un proceso permanente, no conclusivo, que siempre está en movimiento. De ello deriva la necesidad de crear una cultura de la evaluación, donde todas las personas crean que el proceso puede provocar cambios significativos y traer beneficios a la institución. (p. 47)

Na visão de Eyng (2004), a AI é sempre um processo e, para tanto, as etapas: recolher informações, elaborar juízos de mérito, tomar decisões de melhora que conduzam à eleição e aplicação de alternativas de intervenção mais adequadas, devem estar presentes para que, de fato, a avaliação cumpra o seu papel de provocadora de modificações na estrutura e na concepção dos processos que ensejam o desenvolvimento das atividades da universidade.

Com a mesma coerência, Leite (2005) argumenta que a AI tem como propósito avaliar a instituição como um todo, abrangendo todas as dimensões e envolvendo os sujeitos institucionais, referindo-se a um projeto que busca o "balanço dos rumos da 
instituição em busca da qualidade" (p. 33). A avaliação institucional como processo constitui um serviço de prestação de contas à sociedade, à medida que os integrantes da instituição possam repensar seus compromissos e metas, modos de atuação e finalidades de suas práticas e de sua missão. No entendimento de Lampert (1995), a universidade deve discutir a avaliação, mas, sobretudo, realizá-la permanentemente, com adoção de ferramentas e critérios adequados e condizentes à situação.

No processo de AI, estão inseridos momentos distintos que são a avaliação externa, a avaliação interna e a meta-avaliação. São momentos específicos, mas que buscam ou devem apresentar objetivos voltados à melhoria do ensino, bem como do projeto de desenvolvimento institucional, apontando caminhos para a tomada de decisão. Porém, segundo Dias Sobrinho e Ristoff (2000), "esses tipos de avaliação não são necessariamente distintos no tempo. Por ser um processo contínuo, a avaliação institucional vai sempre desenvolvendo procedimentos que devem se unir num significado global” (p. 127).

É indispensável, tanto na avaliação interna como na externa, sopesar o contexto político, econômico, social, cultural, a história e a missão da instituição, pois cada instituição é única, e convém levar em consideração as dinâmicas e os contextos internos e os externos às instituições. Em relação a essa questão, Gatti (2006), se posiciona:

Estando a instituição universitária no seio de uma comunidade mais, e, ao mesmo tempo, a serviço dela, pensando e provendo mudanças societárias, tem seus fundamentos em uma perspectiva sociocultural e ética, para além de seu papel científico. É uma instituição de formação de gerações humanas em uma certa direção civilizatória, que comportaria uma perspectiva sobre o conhecimento - o que se constrói e o que se transmite - como meio para viver melhor num coletivo compartilhado. (p. 10)

Colocando o foco da AI no seu sentido formativo, mais do que um simples processo informativo e estabelecendo um caráter educativo, é que será possível instaurar um sentido avaliativo com o objetivo de buscar evidenciar o que é preciso mudar e o que é preciso fortalecer e ampliar para a obtenção do sucesso relacionado à qualidade da educação superior. 
Neste raciocínio, Ribeiro (2009) afirma que a validade de um processo de avaliação institucional não deve se limitar ao atendimento de uma exigência legal. As IES precisam responder às obrigações da busca contínua da qualidade no desempenho acadêmico, do aperfeiçoamento constante do planejamento e da gestão universitária e do fortalecimento progressivo dos compromissos sociais na prestação de contas à sociedade. São estes compromissos que mantêm a avaliação na agenda dos principais temas do Ensino Superior na atualidade.

\section{A AVALIAÇÃO INSTITUCIONAL NA PROPOSTA DO SINAES}

O documento oficial, balizador da proposta do Sinaes, oficializou que a AI é o instrumento central, organizador da coerência do conjunto de procedimentos aprovados pela Lei 10.861/2004, para a avaliação da educação superior brasileira. Na avaliação, deverão ser levados em consideração três aspectos: “a) o objeto de análise é o conjunto de dimensões, estruturas, relações, atividades, funções e finalidades de uma IES; dentre outros aspectos, ensino-pesquisa-extensão, administração, responsabilidade e compromissos sociais, formação, etc; b) os sujeitos da avaliação são os conjuntos de professores, estudantes, funcionários e membros da comunidade externa especialmente convidados ou designados; e c) os processos avaliativos seguem os procedimentos institucionais e se utilizam da infraestrutura da própria instituição (SINAES, 2007, P.98-100). A proposta enfatiza como objetivos “conhecer as fortalezas e os problemas da instituição, tratar da adequação de seu trabalho com respeito às demandas sociais, as clássicas e as novas, identificar os graus de envolvimento e os compromissos de seus professores, estudantes e servidores tendo em vista as prioridades institucionais básicas" (SINAES, 2007, P.101). Acrescentou-se uma lista de questões para a IES avaliar: desenvolvimento do ensino, a formação profissional e cidadã, o destino profissional e social dos ex-alunos, a adequação dos critérios de aprovação e promoção, carreira docente, e outros. Além disso, hoje, a sociedade exige a prestação de contas das ações do Estado e, por isso, assegurar a qualidade da educação é uma prerrogativa do poder público, cabendo-lhe 
não somente traçar as diretrizes e fazer o acompanhamento, mas a função é mais ampla. Deve-se, pois, supervisionar as atividades das instituições, estimular a correção de rumos, informar a sociedade e tomar as providências recomendáveis quando couber (SinAes, 2007).

Com base nessas prerrogativas é possível pensar que o poder público confere a si, a prerrogativa de tornar a avaliação um instrumento de controle tão somente do produto, não se importando com o processo, ou seja, em quais condições a educação se realiza. Nesse sentido, adultera-se a verdadeira vocação das avaliações, a de serem sempre pedagógicas no sentido de que estimulam valores e não de "detentores de suprapoderes" (LeITE, 2005, P. 34). Este reforço é dado pelo documento oficial que preconiza para as IES o que elas devem avaliar nos seus contextos. Estas determinações assumem proporções enormes e de difícil contemplação, em face da real situação das IES públicas ou privadas. Para além do diagnóstico, "não basta levantar as deficiências, é também muito importante identificar as qualidades e os aspectos fortes da IES” (SINAEs, 2007, P. 101). As IES deverão, ainda, providenciar a elaboração do planejamento que contenha os itens: explicação das possibilidades reais de superação, estabelecimento das ações adequadas e os meios necessários para a promoção das alterações.

Dias Sobrinho (2003, P. 61) enfatiza que a AI deve ser promovida como um processo de caráter essencialmente pedagógico. Não se trata apenas de conhecer o estado da arte, mas também de construir, [...] reconhecer as formas e a qualidade das relações na instituição, constituir as articulações, integrar as ações em malhas mais amplas de sentido, relacionar as estruturas internas aos sistemas alargados das comunidades acadêmicas e da sociedade. Os interesses da instituição não são suficientes. É necessário o compromisso de todos os segmentos com a participação dos envolvidos no processo, nas diferentes etapas: pensar, elaborar e executar. Nessa linha de pensamento, Holgado Sánchez e Lampert (2002, p. 224) afirmam que:

El proceso de evaluación tiene que tener la participación de los distintos sectores, categorías profesionales, alumnado, tanto en la discusión y planificación, como en la ejecución del proceso evaluativo. La evaluación, para tener credibilidad y legitimidad, debe ser resultado de una construcción 
Posto isso, fica evidente a notoriedade que a autoavaliação institucional passa a assumir no novo contexto de avaliação da educação superior no Brasil. É sob esse ponto de vista que, a seguir, iremos discorrer sobre os aspectos conceituais e metodológicos dessa dimensão da avaliação institucional.

\subsection{FUNDAMENTOS DA AUTOAVALIAÇÃO INSTITUCIONAL (AAI)}

A Lei n. 10.861/2004 previu que o ponto de partida dos processos que constituem o sistema de avaliação da educação superior situa-se em cada instituição. Por esse entendimento legal, todas IES que fazem parte do sistema federal de educação superior tiveram que dar início ao seu próprio processo de autoconhecimento. A AAI deve ser realizada pelas instituições, a cada três anos, sendo que os resultados disponíveis deverão, anualmente, ser apresentados à comunidade. A AAI é o primeiro instrumento a ser incorporado ao conjunto de instrumentos constitutivos do Sinaes e seus mecanismos devem ser capazes de compreender o que está acontecendo na instituição, possibilitando correções imediatas para os casos que forem detectados ou diagnosticados. De acordo com o documento base oficial, a AAI será o instrumento "básico obrigatório e imprescindível para todos os atos de regulação, cujo exercício é prerrogativa do Estado. Por outro lado, toda regulação se fará de modo articulado à autoavaliação" (SINAES, 2007, P. 102). A lei, ainda, sublinha a importância de que os processos avaliativos se tornem permanentes, aderindo e compondo a dinâmica institucional, e que eles devam "constituir-se como uma cultura internalizada nas estruturas e nas ações institucionais (SinAes, 2007, P. 106).

Holgado Sánchez e Lampert (2002) apontam o escopo da AAI com potencial de transformação em relação à avaliação externa e alertam para as características imprescindíveis a esse processo: 


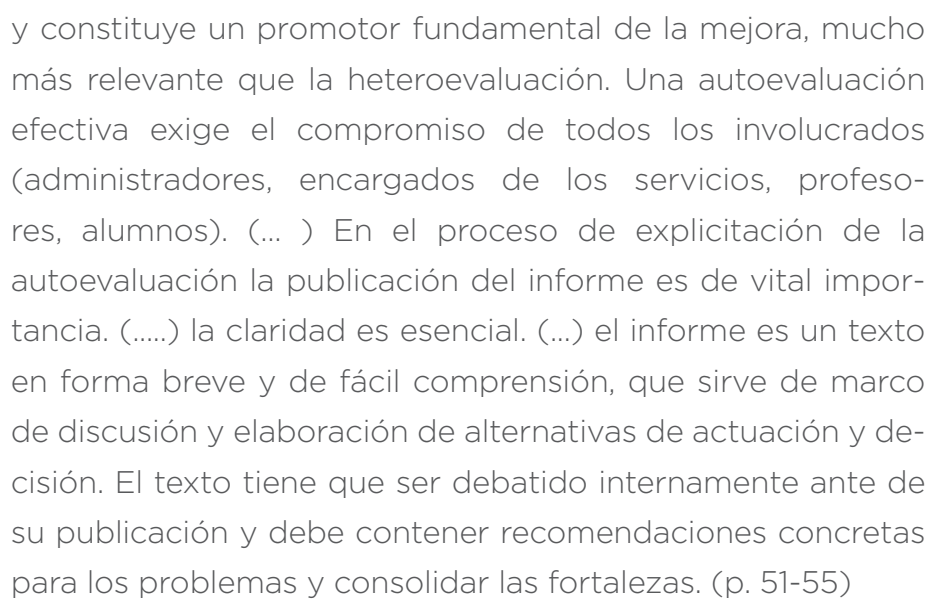

E para que esse processo tenha êxito, não é suficiente a existência de um coordenador que tenha feito um "curso" ou que a instituição tenha uma Comissão Permanente de Avaliação (CPA) constituída. O que de fato importa e faz toda diferença é como os envolvidos no processo concebem a avaliação, ou seja, qual o significado da autoavaliação para os atores institucionais.

As orientações ensejadas pelos autores destacados para o sucesso de um programa de autoavaliação foram também anunciadas no documento oficial: existência de uma equipe de coordenação; participação dos integrantes da instituição; compromisso explícito por parte dos dirigentes das IES, informações válidas e confiáveis; e o uso efetivo dos resultados. O êxito do processo está intimamente relacionado com a existência, dentro de cada universidade, de uma comissão a se responsabilizar pela condução do processo de autoavaliação (SINAES, 2007).

\section{OS PROCESSOS E AS PRÁTICAS DE AUTOAVALIAÇÃO} NAS IES PÚBLICA E PRIVADA

3.1 A PERCEPÇÃO DOS AUTORES INSTITUCIONAIS SOBRE A CONSTRUÇÃO E IMPLANTAÇÃO DA PROPOSTA DE AUTOAVALIAÇÃO INSTITUCIONAL

Nos dois universos das IES - o público e o privado -, o processo de autoavaliação institucional vem se desenvolvendo 
de acordo com as seguintes fases: i) segundo semestre de 2004, com a obrigatoriedade da AAI, deu-se início ao processo de construção coletiva da proposta de autoavaliação; ii) começo de 2005 ao final de 2006, período caracterizado de "euforia" institucional, sobremaneira, pela atuação da CPA, resultando na elaboração do $1^{\circ}$ relatório de AAI e seu envio à Conaes; iii) início de 2007 ao final de 2008, socialização dos resultados da AAI e expectativa da comunidade para o recebimento das comissões externas de avaliação para o fechamento do $1^{\circ}$ ciclo; iv) agosto de 2008 até o início de 2009, a AAI perde destaque internamente, influenciada pela condução dada pelo MEC para a avaliação das instituições ${ }^{3}$; contudo as IES deram prosseguimento à avaliação institucional. Com isso, podemos inferir que a avaliação institucional está incorporada nos processos e nas práticas das IES.

Mediante a análise das propostas de AAI e das entrevistas dos dirigentes, foi possível indicar que as IES, sob a condução da CPA, elaboraram seus projetos de AAI em concordância com os princípios, as dimensões e os indicadores presentes no texto legal, no documento base e no roteiro de AAI previstos no Sinaes. A proposta de AAI do UNIARAXÁ incorporou ao seu texto a experiência anterior de avaliação, que era desenvolvida de forma sistematizada e contínua desde 2000. Em relação à proposta da IES pública, esta foi totalmente elaborada em consonância com as orientações do documento base oficial.

Fato interessante sobre a construção das propostas de AAI está relacionado à maneira pela qual a CPA foi constituída e formada nas duas IES. Prevaleceu a forma indireta de escolha dos seus membros e a maioria daqueles que participaram da primeira comissão foram reconduzidos a um segundo mandado. Ficou evidente, nas entrevistas, que os atuais dirigentes não pretendem alterar essa prática de composição da CPA no sentido de se criar um modelo mais democrático que venha garantir a participação de pessoas “distantes" do grupo gestor.

Quando se trata da autonomia das CPAs, identificou-se que esta foi estabelecida com mais nitidez no âmbito interno, pelo trabalho de estruturação e seleção dos procedimentos, a
3 Rothen e Barreyro (2009),

no artigo: "Avaliação da educação superior no segundo governo Lula:

"Provão II" ou a reedição de velhas práticas? Com bastante propriedade realizam um estudo minucioso da alteração
da lógica avaliativa do Sinaes, indicando tanto as normas subsequentes quanto diversos fatos divulgados pela mídia escrita nacional. 
promoção de eventos sobre o Sinaes para a comunidade e a socialização dos resultados. Já, no âmbito externo, é forte a subordinação e a dependência às orientações, sugestões e roteiros originários do poder governamental.

Um elemento investigado na pesquisa foi a identificação de qual concepção de avaliação é predominante entre os dirigentes e o nível de importância da avaliação da educação superior e, especificamente, a avaliação institucional para as IES. O resultado indicou que os dirigentes da IES pública e da privada compreendem a avaliação institucional como um mecanismo que vai além do diagnóstico da realidade acadêmico-administrativo; é um mecanismo que se sobressai, na medida em que ultrapassa os seus limites técnicos e se complementa com a dimensão política que toda avaliação domina. Impera uma visão de que a avaliação é um verdadeiro instrumento de mudança, de promoção da melhoria pedagógica e que os seus resultados não devem servir à premiação ou punição. A visão dos dirigentes sobre as finalidades da avaliação da educação superior foi a de que esta deve servir para criar referentes organizadores da atividade acadêmica para as IES, para o governo e para a sociedade.

Nesta perspectiva, os docentes da IES privada, 78\% dos participantes, têm uma concepção de avaliação institucional associada a um processo formativo e pedagógico que visa à melhoria e ao crescimento da instituição e dos envolvidos. Enquanto que para $18 \%$ dos docentes, o processo de AAI não é apropriado; ainda não se ajustou às necessidades almejadas. Os docentes da IES pública, 60\% dos participantes, indicaram uma concepção de autoavaliação pautada na perspectiva de avanço e melhoria da educação.

Ainda sobre a implantação da AAI os docentes têm uma representação bastante positiva sobre a função da avaliação. Na percepção desses docentes, a função da avaliação institucional deveria ser: induzir à melhoria dos processos internos das IES para garantir uma educação de melhor qualidade. $90 \%$ dos docentes esperam que um processo de autoavaliação contemple as seguintes características: "qualidade”, "melhoria”, "mudanças”, “continuidade”, “reflexão”, “ação”, "transparência”, “ética”. 
Em relação à execução da AAI, na instituição privada e na pública, identificou-se que foi estabelecido uma movimentação interna sem precedentes, tanto na dinâmica acadêmica quanto na administrativa, afetando de imediato a gestão da instituição, que se viu obrigada a providenciar os recursos necessários para o atendimento da proposta. Na IES privada, as formas, os tempos e os espaços de discussão coletiva tiveram que ser criados, pois assim exigia a concepção de AAI defendida no Sinaes. Já na IES pública, esse espaço de discussão coletiva foi reprogramado e ampliado, haja vista que a instituição, pela sua estrutura e quantidade de órgãos colegiados existentes, estava mais habituada e capacitada com essa prática. No campo da comunicação interna, os procedimentos foram mais valorizados e incentivados tanto na privada quanto na pública; os setores tiveram que incrementar a comunicação, "pensar diferente”, pois, agora, as ações deveriam ser implementadas em conjunto para o atendimento à dimensão, planejamento e avaliação, especialmente em relação aos processos, aos resultados e à eficácia da AAI.

Constatou-se que a participação da comunidade acadêmica como elemento garantidor da qualidade do processo de AAI está proporcionalmente relacionado à intensidade do envolvimento dos integrantes, tanto nas discussões iniciais sobre a concepção, as finalidades e o desenho da avaliação, quanto à atuação no levantamento e na organização das informações e dados das pesquisas e das interpretações que dão continuidade ao processo avaliativo. Nas duas instituições, a participação da comunidade foi mais evidente no momento da socialização dos resultados do que nas outras etapas. O envolvimento do discente, na AAI, tende a ser menor quando as estratégias e as ações que envolvem a prática da meta-avaliação não contemplam esse segmento de maneira significativa, apontaram os discentes pesquisados.

As dificuldades distinguidas pelos dirigentes para a execução da AAI relacionaram-se a duas categorias: recursos humanos e recursos materiais. Na IES pública, a carência de recursos humanos ficou mais destacada, mas, além da carência de servidores, há a deficiência de pessoal com formação 
e experiência em avaliação de instituições, o que foi identificado também na IES privada. Outra dificuldade listada foi a da rotatividade das pessoas que integram o grupo gestor de acompanhamento e execução da AAI, tanto na pública quanto na privada, pois a indicação de pessoas para atuarem assume a tendência mais de critério político do que técnico. Na categoria de recursos materiais, os dirigentes foram unânimes em dizer que existem dificuldades para a instalação adequada da CPA, em espaço confortável e adequado às condições de funcionamento, e outra grande dificuldade é relativa à capacidade do gerenciamento e tratamento das informações levantadas e à funcionalidade do sistema no que tange ao acesso, tratamento estatístico e emissão dos relatórios.

\subsection{A PERCEPÇÃO DOS ATORES INSTITUCIONAIS SOBRE A INCORPORAÇÃO DOS RESULTADOS DA AUTOAVALIAÇÃO INSTITUCIONAL NA PRÁTICA DOCENTE}

A credibilidade em quem avalia é fator importante para se assegurar a continuidade e a validade dos resultados da avaliação. As evidências apontaram que os docentes aprovam o discente como agente avaliador do seu desempenho. Outros elementos são necessários à consolidação da cultura da AAI: construção da proposta pelo/no coletivo amplamente discutida, as ideias dos envolvidos colocadas em discussão e apreciadas e as regras previamente divulgadas e compreendidas. A contemplação disso mobiliza para a instalação de uma segurança jurídica entre as partes e, por consequência, minimiza reações de mal-estar aos efeitos da avaliação. Os efeitos adversos da AAI foram assim identificados: para os docentes da IES pública os resultados têm um impacto psicológico menor, portanto, é menos evidente a modificação da atuação do professor; os docentes recebem o resultado com mais tranquilidade e a avaliação do discente tem peso menor; para os docentes da IES privada, os resultados da avaliação provocam as seguintes atitudes: $78 \%$ de aceitação, 16\% de negação e 6\% de indiferença.

Conforme mostrou os dados da pesquisa, os resultados da avaliação docente têm forte tendência para provocar alterações em alguns aspectos da atuação do professor. 95\% dos docentes da IES privada e da pública responderam da seguinte forma 
acerca dos efeitos da avaliação na alteração da atuação: "sim" e as variantes, "certamente", "com toda certeza”, "muito". Confirmou-se que os resultados contribuem positivamente tanto para os docentes com mais anos de experiência na docência, quanto para aqueles que estão no início da carreira. Esse "achado" reforça a ideia de que o papel de divulgação, sensibilização e socialização dos resultados colaboram para a criação do vínculo entre o resultado da avaliação e a consequente tomada de decisão.

A porcentagem de $91 \%$ e $97 \%$ dos discentes, da IES privada e da pública respectivamente, considera muito importante avaliar o desempenho docente. Este índice corrobora a reflexão de que o aluno é autor essencial no processo de avaliação docente, como afirma Lampert (1995) ${ }^{4}$ e outros autores ${ }^{5}$ que consideram a opinião dos alunos como fonte principal para a avaliação docente.

Para $32 \%$ e $20 \%$ dos discentes, da IES privada e da pública respectivamente, os docentes apresentaram alteração na condução das aulas após os resultados da avaliação docente. A alteração da prática docente englobou as dimensões: i) entusiasmo e compromisso pela tarefa docente; ii) gestão do processo ensino-aprendizagem; iii) clareza e objetividade na condução da aula; iv) domínio do conteúdo/avaliação e v) formalidade/material didático.

Os resultados desta pesquisa apontam que os resultados da avaliação docente produzem alteração mais perceptível na atuação do docente da IES privada e de forma imediata nos aspectos: "comprometimento", "dedicação", "atenção", "paciência”, "tratamento" e "educação com os alunos”, "prestatividade", "entusiasmo", "entendimento entre aluno e professor", "atenção às sugestões”, "comunicação entre aluno e professor", "relacionamento com a turma", contidos na dimensão, Entusiasmo e compromisso pela tarefa docente, conforme apontado pelos discentes. Na IES pública, a dimensão mais enfatizada também foi Entusiasmo e Compromisso pela Tarefa Docente; entretanto, o aspecto, "disposição para dar aula”, o mais evidenciado pelos discentes.
$4 \bigcirc$ autor ressalva que alguns aspectos são mais difíceis de serem avaliados pelo discente devido à especificidade da ação docente. Ele exemplifica os aspectos considerados difíceis de serem avaliados: "adequação e validade dos objetivos (conteúdos e princípios da disciplina) atualização do material pedagógico; domínio e profundidade do conteúdo: indicação de bibliografia atualizada; validade das leituras exigidas e preparação das aulas" (p. 14).

5 Lampert (1995, p.11) cita os autores: (Tejedor, Jato Seijas, Miguez Rodrigues (1998), Tejedor e Montero (1990) Moreira (1986), Apodaka e outros (1990), Blanco, Pacheco e Silva (1988), Nadeau (1988) Ahumada Acevedo (1992) Castro (1991), Moreira (1981), Pasquali (1984)

\section{CONSIDERAÇÕES FINAIS}

Percorrido este caminho de análise do processo de construção, execução e incorporação dos resultados da avaliação docente, 
ficou evidente que na AAI, embora seja um mecanismo relativamente recente, os resultados já produzem repercussões consideráveis e efeitos na dinâmica administrativa e acadêmica nas IES e nos atores institucionais. A avaliação institucional está incorporada nos processos e nas práticas das IES.

A preocupação constante dos dirigentes, docentes e discentes foi com a melhoria e o aperfeiçoamento do processo de AAI. Para tanto, a crítica consensual foi a de que para se estabelecer a cultura da avaliação institucional é necessária a efetivação da meta-avaliação. Ou seja, avaliar o processo de avaliação em curso, informá-lo à sociedade e tomar as providências recomendáveis, quando couber.

Por fim, em um processo de avaliação docente, quanto mais os envolvidos observarem que o processo resultará em sugestões para a melhoria das atividades desenvolvidas e estabelecerá alguma forma de incentivo à capacitação, os docentes tenderão a se envolverem e aceitarem a proposta de AAI.

Consideramos, ainda, pertinente o adensamento de pesquisas que busquem investigar aspectos relativos à docência universitária que estão sendo alterados, modificados ou ressignificados a partir desse cenário em que os processos de avaliação institucional estão em transformação. Além disso, é importante considerar que o Sinaes é uma política de avaliação flexível, dinâmica e em construção, e o seu futuro dependerá mais daqueles que creditam na avaliação uma condição imprescindível para o fortalecimento e a comunicação da universidade com a sociedade, mais do que a condução governamental dessa política de avaliação.

\section{REFERÊNCIAS BIBLIOGRÁFICAS}

BARDIN, L. Análise de conteúdo. 5.ed. Lisboa: Edições 70, 1999.

BELLONI, I. A Função social da avaliação institucional. In: DIAS SOBRINHO, J.; RISTOFF, D. I. Universidade desconstruída: avaliação institucional e resistência. Florianópolis: Insular, 2000.

BRASIL. Instituto Nacional de Estudos e Pesquisas Educacionais Anísio Teixeira. SINAES - Sistema Nacional de Avaliação da Educação Superior: da concepção à regulamentação. 4.ed., ampl. Brasília: Inep, 2007. 
Estado e o Mercado. Educação \& Sociedade. Campinas, v. 25, n. 88, p. 977-996, Especial - out. 2004.

COELHO, I. M. Avaliação Institucional na Universidade Pública. In: DIAS SOBRINHO, José; RISTOFF, Dilvo Ilvo. Universidade desconstruída: avaliação institucional e resistência. Florianópolis: Insular, 2000. p. 59-72.

DIAS SOBRINHO, J. Avaliação quantitativa, avaliação qualitativa: interações e ênfases. In: SGUISSARDI, Valdemar (Org.). Avaliação universitária em questão: reformas do Estado e da educação superior. Campinas: Autores Associados, 1997.

. Avaliação da Educação Superior. Petrópolis: Vozes, 2000. . Avaliação: políticas educacionais e reformas da Educação Superior.

São Paulo: Cortez, 2003.

Avaliação ética e política em função da educação como direito público ou como mercadoria? Educação \& Sociedade, Campinas, v. 25, n. 88, p. 703-725, Especial, out. 2004.

EYNG, Ana Maria. A Avaliação como estratégica na construção da identidade institucional. In: Revista Avaliação, n. 3, p. 42-43, set. 2004.

GADOTTI, M. Concepção dialética da avaliação. In: DEMO, P. Avaliação qualitativa. Campinas: Autores Associados, 1995. p. 1-5.

GATTI, B. A. Avaliação institucional: processo descritivo, analítico ou reflexivo? Estudos em Avaliação Educacional, São Paulo, v. 17, n. 34, p. 7-14, p. 103-114, maio/ago. 2006.

HOLGADO SÁNCHEZ, M. A.; LAMPERT, E. Evaluación de la Universidad de la Experiência: desafios y perspectivas para el siglo XXI. Salamanca: Kamos, 2002.

LAMPERT, E. Avaliação do desempenho do professor universitário. Salamanca: Kadmos, 1995. (extracto de la tesis presentada para la obtención del grado de doctor).

. Avaliação institucional: qual a ideologia subjacente a este processo. Evidência: olhares e pesquisa em saberes educacionais. Araxá, v. 4, p. 149-174, 2008.

LAMPERT, E.; HOLGADO SÁNCHEZ, M. A. La Creación de cultura de evaluación institucional. Anales de Pedagogía, Múrcia, n. 19, p. 221-240, 2001.

LEITE, D. Reformas universitárias: avaliação institucional participativa. Petrópolis: Vozes, 2005.

POLIDORI, M. M.; FONSECA, D. G. da; LARROSA, S. F. T. Avaliação institucional participativa. Avaliação, Campinas; Sorocaba, v. 12, n. 2, jun. 2007. Disponível em: <http://www.scielo.com.br>. Acesso em: 18 ago. 2009.

RIBEIRO, E. A. Políticas públicas para a Educação Superior: a percepção dos docentes sobre os impactos da avaliação institucional. Evidência: olhares e pesquisa em saberes educacionais, Araxá, v. 5, n. 5, p. 71-92, 2009. 
2010. 330f. Tese (doutorado) - Faculdade de Educação. Universidade Federal de Uberlândia, Uberlândia.

RISTOFF, D. I. A tríplice crise da universidade brasileira. In:

Universidade em foco: reflexões sobre a educação superior. Florianópolis: Insular, 1999, p. 21-32.

SANTOS, Boaventura de Souza. A Universidade no século XXI: para uma reforma democrática e emancipatória da Universidade. 2.ed. São Paulo: Cortez, 2005.

\section{ELISA ANTONIA RIBEIRO}

Doutora em Educação pela Universidade Federal de Uberlândia. Atua como professora no Instituto Federal de Educação, Ciência e Tecnologia do Triângulo Mineiro (IFTM)

elisa.ribeiro@iftm.edu.br 